\title{
Determinants and Prevalence of Impotence among Diabetic Patients in Northwestern Hospitals of Nefasit, Eretria
}

This article was published in the following Dove Press journal: Diabetes, Metabolic Syndrome and Obesity: Targets and Therapy

\author{
Girish Degavi (iD) \\ Hazaratali Panari ${ }^{2}$ \\ 'Department of Nursing, College of \\ Health and Medical Science, Bule Hora \\ University, Hagere Mariam, Ethiopia; \\ ${ }^{2}$ Department of Nursing, Institute of \\ Medicine and Health Sciences, Debre \\ Berhan Univerity, Debre Berhan, Ethiopia
}

Correspondence: Girish Degavi Department of Nursing, College of Health and Medical Science, Bule Hora University, P.O Box 144, Hagere Mariam, Ethiopia

Email girishdegavil984@gmail.com
Background: Impotence incidence in patients with elevated glycemic index valuesis $30 \%$ $69.01 \%$. While impotence is very prevalent among diabetic men, the condition is mostly left unaddressed and needs assessment and care. Impotence can influence the quality of social, mental, leisure, and sexual life, and can contribute to broken relationships, depression, and reduced selfesteem. The goal of the present work was to research the commonness and determinants of impotence among diabetic patients in hospitals in the northwestern region of Nefasit .

Methods: A cross-sectional hospital analysis was done of 239 patients with diabetes mellitusin five of six hospitals in Nefasit by means of systemic random sampling. methods. Data were collected for 2 months from Februaryto April 2019.

Results: The mean age of participants was 43.32 years and mean duration of diabetes 8.7 years. Impotence prevalence was found to be $74.2 \%: 36.1 \%$ mild, $34.2 \%$ moderate, and $5.8 \%$ serious sexual dysfunction. Statistical analysis showed that impotence was considerably associated with being elderly (AOR 14.21, 95\% CI 3.22-70.00), prolonged diabetes (AOR 4.1, 95\% CI 1.22-11.16), and lower monthly income (AOR0.279, 95\% CI 0.133-0.614). There was no association found with BMI, comorbidity, sugar control, or intake of alcohol. Conclusion: The prevalence of impotence in the present study was quite high. Very few patients $(5.1 \%)$ had been screened for impotence. Care of impotent patients in hospitals for diabetes should be a regular health protocol during follow-up care.

Keywords: Asmara, determinants, DM, Nefasit, prevalence

\section{Introduction}

Impotence is a lack of capacity to generate and maintain a persistent erection for fulfilling sexual activity. In connection with the expanding predominance of diabetes mellitus (DM), complications like impotence are on the rise. ${ }^{1}$ The rate of events of impotence in people with DM is two to three times that of people without DM. People with DM may encounter weakness as much as 10-15 years prior to people without DM. ${ }^{2}$ Research on prevalence of impotence in diabetic men have delivered a range of findings: $35 \%-90 \%$. Sexual dysfunction was found in $>50 \%$ of diabetic men in the US, $79 \%-90 \%$ in Saudi Arabia, 39\% in the Netherlands, 35\%$81 \%$ in Mexico, and $75 \%$ in Isfahan, Iran. ${ }^{3,4}$ Moreover, impotence prevalence was found to be $55.1 \%$ in Tanzania, of which $11.3 \%$ had mild, $10.5 \%$ moderate, and $27.9 \%$ severe dysfunction. Prevalence of impotence reaches $72.5 \%$ in Nigeria., ${ }^{5,6}$

Sexual function is important for quality of life.Sexual dysfunction adversely influences social interactions and emotional and mental health. It is critical to note 
that impotence is one of the foremost mendable problems of DM: $>95 \%$ of patients can be effectively cured. ${ }^{7}$ What makes the condition worse is that numerous males feel too humiliated to reveal and talk about the issue with their specialist or indeed their companions. The problem is more likely to occur in the study area, due to cultural barriers to open discussion of sexual matters.

To the investigators' knowledge, there has not been any similar specific study conducted on diabetic men in the study area, even the country at large. This study sheds light on the sexual well-being of diabetic patients and will contribute to endeavours made in progressing the quality of life of diabetic populace.

\section{Methods}

This clinic-centered transverse study was conducted on 239 male diabetic patients at five clinics in the central and northwestern zones of Nefasit, northern Asmara. These clinics were Saint Yahonas Clinic, Ababe Clinic, Manul Clinic, and Kay Li Clinic. Male diabetic patients aged $\geq 18$ years were included. Those with known auxiliary impotence of hereditary, endocrinological, neurological, or surgical causes were excluded. FData were collected for 2 months from February to April 2019. This was because most of the diabetic patients have appointments every 2 months. To survey erectile function, a pretested questionnaire based on the condensed five-item adaptation of the International Index of Erectile Function (IIEF5) was used. ${ }^{8}$

Information was accumulated from charts, self-report, and other patient documents. Diagnosis of DM is made by doctors working at each study clinic. We utilized the WHO criteria of FBS $\geq 126 \mathrm{mg} / \mathrm{dL}$ as diabetes. FBS was measured utilizing glucometry soon after breakfast when the patients arrived at the clinic. To encourage honest responses on the questionnaire, five male nurses working at the study clinics were enlisted to administer it. The instrument incorporates sociodemographic factors, clinical findings, and other variables. It was translated to the Tigreia dialect and then back-translated into English.t A single-proportion formula was used to calculate test estimates by viewing $95 \%$ CIs with $5 \%$ margin of error. Since there were no known applicable data available for the nation, we used a predominance study done in Nigeria $(39.5 \%)^{9}$

The sample size was decreased utilizing the population-correction formula and including a $10 \%$ nonresponse rate, for a final total of 239. The proportion size at each of the five hospitals was as per the entire populace. Samples are chosen utilizing random sampling $(k=2)$ for DM and persistent infections at the follow-up clinic. Information collectedwas entered and analyzed utilizing SPSS 20.

\section{Results}

\section{Sociodemographic Characteristics}

A total of 239 patients were questioned using systematic random sampling. Feedback was $100 \%$. Participants' mean agewas 43.32 (range 18-81) years.Mean diabetes duration was 8.1 years (range 3 months to 32 years)Almost all (94.14\%) are Tigre in ethnicity, and a majority (87.86\%) married. Religion and education variables showed orthodox of $88.70 \%$ and grade $1-8(46.86 \%)$, respectively.

Regarding occupation, a majority (51.04\%) were farmers, followed by government employees (19.66\%). A significant proportion $(43.51 \%)$ had a monthly income per month $<$ US\$26 (Table 1).

\section{Clinical and Lifestyle Characteristics}

Lifestyle variables showed $38.07 \%$ drank alcohol, $8.78 \%$ smoked cigarettes, and $91.21 \%$ did not undertake regular exercise. The mean FBS of study samples was $187.5 \mathrm{mg} /$ $\mathrm{dL}$, of which $35.98 \%$ were in the universally acceptable normal range $(<126 \mathrm{mg} / \mathrm{dL})$ and $64.01 \%$ above normal $(\geq 126 \mathrm{mg} / \mathrm{dL}$ ), implying that the glycemic status of a majority was poorly controlled.

Mean body-mass index (BMI) was 20.77 (range 13.8$29.4) \mathrm{kg} / \mathrm{m}^{2}: 55.23 \%$ had normal BMI $\left(18.5-24.9 \mathrm{~kg} / \mathrm{m}^{2}\right)$, $34.72 \%$ were underweight (BMI $<18.4 \mathrm{~kg} / \mathrm{m}^{2}$ ), and $10.04 \%$ overweight (BMI $25-29.9 \mathrm{~kg} / \mathrm{m}^{2}$ ), but no obese (BMI $>30 \mathrm{~kg} / \mathrm{m}^{2}$ ) patients were found.

Blood-pressure (BP) measurements showed a majority $(67.78 \%)$ were within the normal range, and the rest (10.04\% and $22.17 \%$, respectively) had stage 1 and 2 hypertension. Manual sphygmomanometry (BP cuff) was used to measure BP, and WHO standards used to categorize BMI.

With respect to comorbidity of the study subjects, 35 (14.64\%) had advanced chronic infections other than DM. The commonest chronic illness coexisting with DM was hypertension, which accounted for $12.13 \%$. For DM type, $69.01 \%$ were type 1 and the remaining $35.98 \%$ type 2 (Table 2).

\section{Prevalence and Determinants of Impotence}

After IIEF5) had been measured, the mean erectile function score is $13.72 \pm 4.38$ (range 5-23). The prevalence of 
Table I Sociodemographic variables related to impotence among diabetic patients

\begin{tabular}{|c|c|}
\hline & n (\%) \\
\hline \multicolumn{2}{|l|}{ Age, years } \\
\hline$<30$ & $62(25.94 \%)$ \\
\hline $30-44$ & $72(30.12 \%)$ \\
\hline $45-59$ & 61 (25.52\%) \\
\hline$\geq 60$ & $44(18.4 \mid \%)$ \\
\hline \multicolumn{2}{|l|}{ Ethnicity } \\
\hline Tigray & 225 (94.14\%) \\
\hline Others & I4 (5.85\%) \\
\hline \multicolumn{2}{|l|}{ Marital status } \\
\hline Married & $210(87.86 \%)$ \\
\hline Single & $22(9.20 \%)$ \\
\hline Separated & $3(1.25 \%)$ \\
\hline Widowed & I (0.4I\%) \\
\hline Divorced & $3(1.25 \%)$ \\
\hline \multicolumn{2}{|l|}{ Religion } \\
\hline Orthodox & $212(88.70 \%)$ \\
\hline Muslim & $24(10.04 \%)$ \\
\hline Others & $3(1.25 \%)$ \\
\hline \multicolumn{2}{|l|}{ Education } \\
\hline Illiterate & $58(24.26 \%)$ \\
\hline Grades I-8 & II (46.86\%) \\
\hline Grades 9-12 & 30 (I2.55\%) \\
\hline College/university & $39(16.31 \%)$ \\
\hline \multicolumn{2}{|l|}{ Occupation } \\
\hline Farmer & $122(51.04 \%)$ \\
\hline Government employee & 47 (19.66\%) \\
\hline NGO employee & $24(10.04 \%)$ \\
\hline Merchant & $20(8.36 \%)$ \\
\hline Daily laborer & 14 (5.85\%) \\
\hline Other & $12(5.02 \%)$ \\
\hline \multicolumn{2}{|l|}{ Monthly income (US\$) } \\
\hline$<25$ & $104(43.51 \%)$ \\
\hline $25-50$ & $62(25.94 \%)$ \\
\hline$>50$ & 73 (30.54\%) \\
\hline
\end{tabular}

impotence was found to be $74.2 \%$, of which $5.8 \%$ had severe, $34.2 \%$ moderate, and $36.1 \%$ mild erectile dysfunction. Only $32.8 \%$ of patients had normal erectile activity. Particularly, the prevalence of erectile dysfunction in type 1 and type 2 DMpatients was $62.2 \%$ and $77.46 \%$, respectively (Figure 1).

Regarding pursuit of a cure, only $12(5.02 \%)$ patients had sought medical help because of erectile dysfunction. In a related finding, just one had been cured by a combination of pharmacological therapy and psychotherapy.
Table 2 Clinical variables among impotent diabetic patients

\begin{tabular}{|c|c|c|c|}
\hline & Impotence & No impotence & Total \\
\hline \multicolumn{4}{|l|}{ Type of DM } \\
\hline 1 & 105 & 48 & 153 \\
\hline 2 & 64 & 22 & 86 \\
\hline \multicolumn{4}{|l|}{ BMI } \\
\hline Underweight & 65 & 18 & 83 \\
\hline Normal & 90 & 42 & 132 \\
\hline Overweight & 15 & 9 & 24 \\
\hline Obese & 0 & 0 & 0 \\
\hline \multicolumn{4}{|l|}{ BP } \\
\hline Normal & 140 & 22 & 162 \\
\hline Stage I & 6 & 18 & 24 \\
\hline Stage 2 & 29 & 24 & 53 \\
\hline \multicolumn{4}{|l|}{ DM duration (years) } \\
\hline$<5$ & 89 & 39 & 128 \\
\hline $5-10$ & 36 & 20 & 56 \\
\hline$>10$ & 38 & 17 & 55 \\
\hline \multicolumn{4}{|l|}{ Smoking } \\
\hline Yes & 17 & 4 & 21 \\
\hline No & 152 & 66 & 218 \\
\hline \multicolumn{4}{|l|}{ Physical exercise } \\
\hline Yes & 42 & 49 & 91 \\
\hline No & 130 & 18 & 148 \\
\hline \multicolumn{4}{|l|}{ Drink alcohol } \\
\hline Yes & 69 & 22 & 91 \\
\hline No & 84 & 64 & 148 \\
\hline \multicolumn{4}{|l|}{ FBS (mg/dL) } \\
\hline$<126$ & 66 & 20 & 86 \\
\hline$\geq 126$ & 98 & 55 & 153 \\
\hline
\end{tabular}

\section{Factors Affecting Erectile Function in Diabetic Patients}

Multivariate logistic regression analysis showed an association between impotence and income, duration, and age of diabetic patients. Respondents aged $>60$ years were around 15 times as likely to be impotent as those in the first three decades of life (AOR 14.21, 95\% CI 3.22-70.10; $P=0.001$ ). Participants who had been diabetic for more than a decade were 4.1 times as likely to develop impotence as those who had been diabetic $<10$ years (AOR 4.1,95\% CI 1.22-11.16; $P=0.015)$. On the other hand, participants who earned $\geq \$ 50$ per month were 0.249 times as likely to be impotent as those earning $<\$ 25 \quad$ (AOR 0.279, 95\% CI 0.1343-0.614; $P=0.001)$. No association was found between impotence 


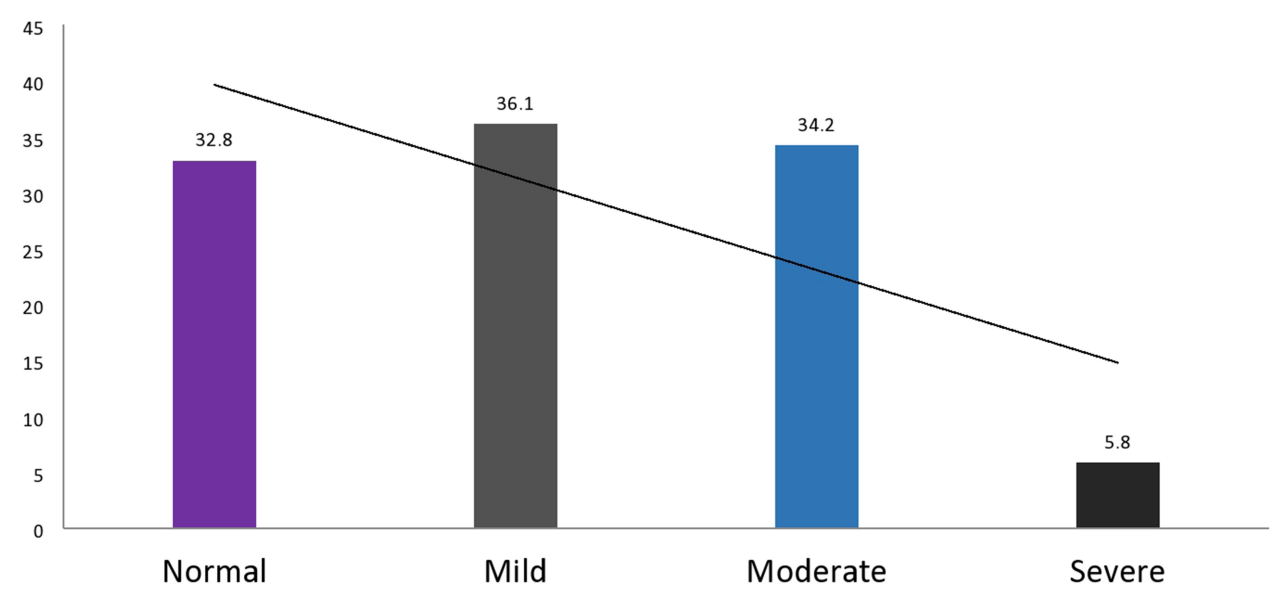

\section{Prevalence of Impotency}

Figure I Prevalence of impotence among DM patients.

Notes: The of impotence incidence was found to be very high. Approximately a third of participants had normal erectile behavior. In fact, the of erectile dysfunction incidence in type I DM patients was significantly lower than in type 2 DM patients.

and BMI, comorbidity, glycemic control, or intake of alcohol (Table 3).

\section{Discussion}

In sum, $30.12 \%$ of type $1 \mathrm{DM}$ patients were $>30$ years of age, and type $2 \mathrm{DM}$ was less common than type 1 . This can be credited to being overweight, which is the most

Table 3 Multivariate logistic regression factors affecting impotence among diabetic patients

\begin{tabular}{|c|c|c|c|}
\hline & AOR & $95 \% \mathrm{Cl}$ & $\boldsymbol{P}$ \\
\hline \multicolumn{4}{|l|}{ Age } \\
\hline$<30$ years & 1.1 & - & - \\
\hline $30-48$ years & 1.14 & $0.489-2.126$ & 0.96 \\
\hline $49-60$ years & 2.18 & $0.909-4.86$ & 0.088 \\
\hline$>60$ years & $|4.2|$ & $3.22-70.10$ & $0.001 *$ \\
\hline \multicolumn{4}{|l|}{ Income (US\$) } \\
\hline$<25$ & I.I & - & - \\
\hline $25-50$ & 0.462 & $0.234-1.011$ & 0.058 \\
\hline$>50$ & 0.279 & $0.133-0.614$ & $0.001 *$ \\
\hline \multicolumn{4}{|l|}{ DM duration } \\
\hline$<5$ years & I.I & - & - \\
\hline $5-10$ years & 1.072 & $0.544-2.012$ & 0.876 \\
\hline$>10$ years & 4.1 & $0.133-11.614$ & $0.014^{*}$ \\
\hline \multicolumn{4}{|l|}{ Comorbidity } \\
\hline No & I.I & - & - \\
\hline Yes & 1.542 & $0.684-3.642$ & 0.34 \\
\hline
\end{tabular}

Note: $* P<0.05$. noteworthy risk factor of type 2 DM. A majority were farmers, comparable to other parts of the nation. This should be explored further, since incommunicable illnesses are also getting to be a dangerous factor for rural communities.

Impotence among patients with DM was $69.9 \%$, among which $5.2 \%$ had severe impotence requiring quick management.Impotence prevalence among men with DM around the world is $35 \%-90 \%$. Our findings concur with data from Nigeria,where impotence prevalence is significantly higher in diabetic patients than other chronic diseases: up to $72.7 \%$. In an Iranian study, sexual dysfunction was identified in $77.5 \%$ of men with DM, and in Saudi patients this is $80 \%-90 \%$. thBe that as it may, there are disparities with studies done in Iran and Tanzania: 55\% and 59.5\%, respectively. This may be ascribed to distinct social and cultural characteristics of participants, methods, and information collection and classification. ${ }^{10}$

DM with impotence has been reported to be $\geq 50 \%$ around the world, which is comparable with this study, and advancedage, chronic DM, comorbidities of hypertension, hyperlipidemia, and glycemic control, cigarette smoking, inactive lifestyle, and obesity are independent risk factors of impotence. This study found that only increased age, longer DM durationDM, and lower pay were related to impotence. This may well be due to inconsistency of methodology, information-collection 
devices, test estimates, and socioeconomic contrasts among study subjects. ${ }^{11}$ On the other hand, studies conducted in Italy and Israel on impotence in both DM types illustrated comparable outcomes for autonomous risk factors. ${ }^{12,13}$

This study further affirms that length of DM, age, and monthly earnings are autonomous risk factors of impotence and its severity, while BMI, glycemic control, and taking DM drugs were not. Maximum ponders have comparable results on age and length of DM as overwhelmingly related factors. Older age-groups, those on lower pay, and patients with long DM duration are more likely to develop impotence. Our result for those aged $>60$ years (AOR 14.21) is similar to Tanzania. Reasons suggested for the increasing rate of impotence in older men have included age-related physiological changes in the testicles and decrease levels iof male sex hormones. ${ }^{5}$

Weight, comorbidity, glycemic control, drinking alcohol, and drug consumption were not associated with impotence in this study, but in others these variables have been associated. ${ }^{4,14}$ As for medicine-seeking behavior of the respondents, among the 169 with impotence, only 12 had visited health-care centers to get treatment, and $94.97 \%$ had not been screened or treated for impotence. This may be attributable to patients feeling embarrassed, believing the condition to be untreatable, fear of side effects of drugs.

\section{Conclusion}

A majority of the patients had uncontrolled glycemic status. Type $1 \mathrm{DM}$ is extra conjoint than type 2. It is significant to reflect as DM would be a risk for rural people. Impotence was more prevalent in type 2 than type $1 \mathrm{DM}$ patients. Very few patients had been screened/treated for impotence. Increased age, poverty, and chronic DM are predictors of impotence.

\section{Abbreviations}

BMI, body-mass index; DM, diabetes; ED, erectile dysfunction; FBS, fasting blood sugar; IIEF, International Index of Erectile Function; NGO, nongovernmental organization; WHO, World Health Organization.

\section{Data Sharing Statement}

Data utilized and assessed in the present study can be obtained from the corresponding author on request.

\section{Ethical Approval}

All studies were conducted in conjunction with the standards for human research set out in the Declaration of Helsinki and recommendations of the International Conference on Harmonisation for good clinical practice, and approved by the relevant institutional review boards of Blue Hora University College of Health and Medical Science. Permission was obtained from medical superintendents at the public clinics and hospitals in this study.

\section{Consent}

Informed written consent was obtained from each research participant after the possible risks and benefits aand purpose of the study had been explained.

\section{Acknowledgment}

The investigators are deeply gratefule to all those who contributed to the successful completion of this endeavor.

\section{Author Contributions}

All authors made a significant contribution to the work reported, whether in conception, study design, execution, acquisition of data, analysis and interpretation, or in all these areas, took part in drafting, revising, or critically reviewing the article, gave final approval to the version to be published, have agreed on the journal to which the article has been submitted, and agree to be accountable for all aspects of the work.

\section{Disclosure}

The authors report no conflicts of interest in this work.

\section{References}

1. National Institute of Health. Consensus development panel on impotence. NIH consensus conference. Impotence. JAMA. 1993;270(1):8390. doi:10.1001/jama.1993.03510010089036

2. National Institutes of Health. Sexual and urologic problems of diabetes; 2008.

3. Sharifi F, M Asghari, Jaberi Y, Salehi O, Mirzamohammadi F. Independent predictors of impotency in Type 2 diabetes mellitus: Is it true what they say about risk factors? ISRN Endocrinol. 2012.

4. Díaz-Díaz E, León MC, Arzuaga NO, et al. Erectile dysfunction: a chronic complication of the diabetes mellitus. In: K. Nunes, Editor. Erectile Dysfunction-Disease-Associated Mechanisms and Novel Insights into Therapy. London, UK: IntechOpen; 2012.

5. Reuben Kato Mutagaywa JL, Aboud M, Kamala BA. Prevalence of erectile dysfunction and associated factors among diabetic men attending diabetic clinic at Muhimbili National Hospital in Dar-es-Salaam, Tanzania. Pan Afr Med J. 2014;17:227. 
6. Lawrence A, OEO-o A, Ladipo MM, Owoaje ET. Prevalence and Correlates of impotency among primary care clinic attendees in Nigeria. Glob J Health Sci. 2012;4(4).

7. Pastuszak AW. Current diagnosis and management of erectile dysfunction. Curr Sex Health Rep. 2014;6(3):164-176. doi:10.1007/ s11930-014-0023-9

8. Rosen RCCJSM, Cappelleri JC, Smith MD, et al. Development and evaluation of an abridged, 5-item version of the International Index of Erectile Function (IIEF-5) as a diagnostic tool for erectile dysfunction. Int $J$ Impot Res. 1999;11(6):319-326. doi:10.1038/sj. ijir.3900472

9. Idung AU, Abasiubong F, Ukott IA, Udoh SB, Unadike BC. Prevalence and risk factors of erectile dysfunction in Niger delta region, Nigeria. Afr Health Sci. 2012;12(2):160-165. doi:10.4314/ ahs.v12i2.13

10. Selvin E, Burnett AL, Platz EA, et al. Prevalence and risk factors for impotency in the US. Am J Med. 2007;120(2):151-157. doi:10.1016/ j.amjmed.2006.06.010
11. Maiorino MI, Bellastella G, Esposito K. Diabetes and sexual dysfunction: current perspectives. Diabetes Metab Syndr Obes. 2014;7:95-105. doi:10.2147/DMSO.S36455

12. Fedele D, Bortolotti A, Coscelli C, et al. Impotency in Type 1 and Type 2 diabetics in Italy. Int J Epidemiol. 2000;29(3):524-531. doi:10.1093/ije/29.3.524

13. Roth A, Kalter-Leibovici O, Kerbis Y, et al. Prevalence and risk factors for impotency in men with diabetes, hypertension, or both diseases: a community survey among 1412 Israeli men. Clin Cardiol. 2003;26(1):25-30. doi:10.1002/clc.4960260106

14. Rad M, Vahdaninia M, Montazeri A. Sexual dysfunctions in patients with diabetes: a study from Iran. Reprod Biol Endocrinol. 2010;8 (50). doi:10.1186/1477-7827-8-50

\section{Publish your work in this journal}

Diabetes, Metabolic Syndrome and Obesity: Targets and Therapy is an international, peer-reviewed open-access journal committed to the rapid publication of the latest laboratory and clinical findings in the fields of diabetes, metabolic syndrome and obesity research. Original research, review, case reports, hypothesis formation, expert opinion and commentaries are all considered for publication. The manuscript management system is completely online and includes a very quick and fair peer-review system, which is all easy to use. Visit http://www.dovepress.com/testimonials.php to read real quotes from published authors. 